\title{
Tokat Koşullarında Arı Otunun (Phacelia tanacetifolia Bentham) Yazlık Ekim Zamanı Ûzerinde Araştırmalar
}

\author{
I- Ot Verimi ile İlgili Özellikler \\ Yaşar KARADAG' \\ Uğur BÜYÜKBURÇ ${ }^{2}$
}

Geliş Tarihi: 17.12.2002

\begin{abstract}
Özet: Tokat koşullarında yazlik olarak yetiştirilen an otunda (Phacelia tanacetifolia Bentham) ekim zamaninın of verimine etkisini saptamak amacıyla yapilan bu araștırma; 2001-2002 yetiștirme sezonlarında Gaziosmanpaşa

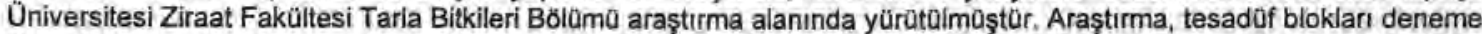
desenine göre üç tekrarlamalı olarak kurulmuştur. Araştırmada, 5 Mart tarihinden başlayarak 15'er gün aralikla 4 farklı ekim zamanı kullaniimıştır. Ekim zamanları arasında; çiçeklenme başlangıcı, bitkide salkım sayısı, bitki boyu, yas ot verimi ve kuru ot verimleri bakımından istatistiksel olarak önemli farkliliklar ortaya çıkmıştır. Araştırmadan elde edilen iki yillık ortalama sonuçlara göre, çiçeklenme başlangıcı $49-68$ gün, bitkide salkım sayısı 5.1-13.2 adet, bitki boyu 38.7 . $54.5 \mathrm{~cm}$, yaş ot verimi $331.5-837.2 \mathrm{~kg} / \mathrm{da}$ ve kuru ot verimi $54.5-220.7 \mathrm{~kg} / \mathrm{da}$ arasında değişim göstermiştir. Bu sonuçlara göre en yüksek bilkide salkım sayısı, bitki boyu, yaş ot verimi ve kuru ot verimi 5 Mart ekim tarihinde ekilen bitkilerden alınmıştır.
\end{abstract}

Anahtar Kelimeler. An otu, ekim zamani, çiçeklenme, kuru ot verimi

\section{Researches on Spring Sowing Date of Phacelia (Phacelia tanacetifolia Bentham) Under Tokat Conditions}

\section{1- Forage Yield Characteristics}

\begin{abstract}
This study was conducted to determine the effect of different sowing dates on the forage yield of Phacelia grown as spring crop in the experimental field of the Agricultural Faculty of Gaziosmanpaşa University in the 2001-2002 growing seasons. This experiment was arranged in a randomized complete block design with three replications. Four different sowing dates were used starting from 5 March and 15 days intervals. It was found that there were statistically significant differences between sowing dates in terms of the beginning of flowering period, number of brunch per plant, plant height, forage yield, hay yield and dry matter ratio. According to two year results, beginnings of flowering period were between 49 and 68 date, numbers of brunch per plant differed from 5.1-13.2, plant heights varied from $38.7-54.5 \mathrm{~cm}$, forage yields were between 331.5 and $837.2 \mathrm{~kg} / \mathrm{da}$ and hay yields differed from 54.5 to $220.7 \mathrm{~kg} / \mathrm{da}$. The highest number of brunch per plant, plant height, forage yield and hay yield were determined at 5 March sowings.
\end{abstract}

Key Words: phacelia, sowing date, flowering, hay yield.

\section{Giriş}

Kuzey Amerika orijinli bir bitki olan an otu (Munz, 1973) polen ve nektar kaynağı olarak oldukça önemli bir bitkidir (Howes 1979). Birçok arı merasında karışımlarda yer alan arı otu son yillarda ülkemizde de yetiştirilmeye başlanmıştır. Arı otu Akdeniz sahil kuşağında başarıyla yetiştirilmektedir. Sonbaharda yapılan ekimlerde Nisan ayı içerisinde çiçeklenebilmektedir (Sağlamtimur ve ark. 1989, Tansı ve ark. 1995). Arı otu, çok değişik kullanim alanlarına sahiptir. Çiçeklerinin bol miktarda polen ve nektar oluşturması yanında, uzun süre çiçekli kalması nedeniyle, Kuzey Amerika ve Avrupa ülkelerinde "Arı Mer'ası" olarak yararlanılmaktadır. Yapılan çalışmalarda anı otunun korunga, fiğ ve kolza ile birlikte aynı dönemlerde yetiştirildiği, iyi çiçek tozu verimine sahip olduğu, arıların arı otunu yoncaya tercih ettiği saptanmıștır (Packer 1973. Peter 1973). Diğer yandan, arı otu bal arılanı için iyi bir nektar kaynağı olarak arıcılar tarafından yaygın olarak kabul edilmekte ve arı otunun dönyadaki ilk yirmi bal bitkisi arasında siralamaktadir (Crane ve ark. 1984).
Çoğunlukla an mer'ası olarak yararıanılan arı otu, yem üretimine de uygun bulunmaktadır (Sağlamtimur ve ark. 1988, Karadağ ve Büyükburç 2001 a, 2001 b). Borowiec ve Pawlus (1973), ar otunun baklagillerle birlikte destek bitkisi olarak yetiștirildiğini ve an otu + baklagil karışımından 1660-1880 kg/da arasında yeșil ot verimi elde ettiklerini bildirmektedirler. Sağlamtimur ve ark. (1989), Çukurova koşullarında kışlik ara ürün olarak arı otunda biçim zamaninin bitki boyu ve ot verimine etkisini incelediği bir araştırmada, sirasıyla bitki boyunu 104-118 cm. yaş ot verimini $1850-3458 \mathrm{~kg} / \mathrm{da}$ ve kuru madde verimini $528-768 \mathrm{~kg} / \mathrm{da}$ olarak belirlemişlerdir. Karadağ ve Büyükburç (1999), Tokat koşullarında yazlık olarak yetiştirien arı otunun verim ve adaptasyonu üzerine yapmış oldukları bir araştırmada, sırasıyla ortalama bitki boyunu $67.77 \mathrm{~cm}$, yaş ot verimini $675.05 \mathrm{~kg} / \mathrm{da}$ ve kuru ot verimini $197,40 \mathrm{~kg} / \mathrm{da}$ olarak tespit etmişlerdir.

\footnotetext{
' Gaziosmanpaşa Öniv. Ziraat Fak. Tarla Blıkileri Bölümu - Tokat

${ }^{2}$ Harran Univ, Ziraat Fak. Tarla Bitkileri Bölümü - Sanliurfa
} 
Karadağ ve Bûyûkbuiŗ̧ (2001 a), an otu bitkisinde ortalama bitki boyunu $67.78-97.43 \mathrm{~cm}$, yas of verimini $1144-2563 \mathrm{~kg} / \mathrm{da}$ ve kuru ot verimini $197-427 \mathrm{~kg} / \mathrm{da}$ arasında değiştiğini bildirmişlerdir. Arı otunun kışıık olarak sira aralığının ot verimi üzerine yapılan bir denemede, ortalama bitki boyu 97.3-107.5 $\mathrm{cm}$,yas ot verimi 1061.3 $1685.1 \mathrm{~kg} / \mathrm{da}$ ve kuru of veriminin $333.8-521.1 \mathrm{~kg} / \mathrm{da}$ arasında değiştiği bildirilmiştir (Karadağ ve Buyūkburç, 2001 b). Bilgen (1999), an otunda ortalama bitki boyunun 31.807-65.010 cm arasında değiștigini tespit elmiştir. Williams ve Christian (1991), Phacelia tanacetifolia Bentham uzerine Güneydoğu Ingiltere'de yüutmüş oidukları bir çalıß̧mada, Mayıs başında ekilen parselin Temmuz başından Ağustos sonuna kadar, Mayıs sonunda ekilen parselin Temmuz ortasından Eylul ortasına kadar çiçeklendiğini ve Temmuz sonunda ekilen parseldeki bitkilerin ise Eylol sonundan itibaren çiçeklenmeye başladığı ve Kasımı ayı soğuklarında görülen bitki ölümlerine kadar devam ettiğini bildirmişlerdir.

Bu araştırma, Tokat-Kazova koşullarında yazlik olarak ekilen an otunun ot verimi yönünden en uygun ekim zamanının saptanması ve bu özellikıer yŏnünden ilişkilerini incelemek amacıyla ele alınmıştır.

\section{Materyal ve Yöntem}

Bu araştırma, Gaziosmanpașa Üniversitesi Ziraat Fakültesi Taşıçiflik Kampüsū deneme tarlasında 2001 ve 2002 yetiştirme peryodunda iki yil süre ile yürütülmüştür. Araștırmanın yürctúldüğa aylar ve ayni aylann uzun yillar iklim verileri Çizelge 1'de verilmiştir.

Çizelge 1'de araştırmanin yüratüldağa aylar ve aynı ayların uzun yıllar aylık sıcaklık ortalaması sırasıyla 14.9 , 13.7 ve $13.9^{\circ} \mathrm{C}$, aylık toplam yağış miktarı ise 156.7 , 172.0 ve $203.3 \mathrm{~mm}$ olarak kaydedilmiştir. Araștırma alanı. toprak tekstürü bakımından killi-tın bir yapıya sahiptir. Organik madde miktarı \% 1.45, kireç \% 10.9, yararlanilabilit fosfor $6.30 \mathrm{~kg} / \mathrm{da}$, yararlanilabilir potasyum $53.4 \mathrm{~kg} / \mathrm{da}$ ve $\mathrm{pH}$ değeri $8.04^{\prime}$ dor. Araştırmada bitki materyali olarak, Çukurova Universitesi Ziraat Fakültesi Tarla Bitkileri Bölümü'nden temin edilen Turan-92 arı otu (Phacelia tanacetifolia Bentham) çeşidi kullanilmıştır.

Araştırma, 2001 ve 2002 yilları arasında lki yil süreyle Gaziosmanpaşa Öniversitesi Ziraat Fakültesi Taşlıçiftlik Kampüsū deneme tarlalarında yapilmıştır. Deneme, tesadüf bloklari deneme desenine göre ọ̄ tekrarlarnalı olarak kurulmuştur. Ekilecek tohum miktarı dekara $2 \mathrm{~kg}$ tohum ízerinden hesaplanmıştı (Sağlamtimur ve ark. 1988, Karadağ ve Büyükburç 2001a). Ekim zaman darak 5 . Mart tarihinden itibaren her 15 gûnde bir ekim olacak şekilde 4 ayri ekim zamanında, tohumiar $40 \mathrm{~cm}$ sira arasi, 6 sira ve $5 \mathrm{~m}$ uzunluğundaki parsellere ekilmiştir. Ekimle birlikte $10 \mathrm{~kg} / \mathrm{da}$ diamonyum fosfat gübresi verilmiştir. Ölçüm işlemleri ve hasat her parselin her iki yanlarındaki birer sıra ve sıra başlarında 0.5 er m kenar tesiri bırakıldıktan sonra geriye kalan $4 \mathrm{~m}$ uzunluğundaki 4'er sırada bulunan bitkilerde yapilmiștır. Parsellerin yarısı ot hasadı amacıyla \% 50 çiçeklenme döneminde (Mayıs ayının ilk haftasından-Haziran ayının ikinci yarısına kadar sürmüștür) biçilmiştir (Sag̈lamtimur ve ark. 1989). Hasat edilen parsellerde çiçeklenme başlangıcı (gön), bitkide salkım sayısı (adet/bitki), bitki boyu (cm), yaş ot verimi ( $\mathrm{kg} / \mathrm{da}$ ) ve kuru ot verimi ( $\mathrm{kg} / \mathrm{da}$ ) belirlenmiştir.

Araștırmadan elde edilen sonuçlar Düzgüneș ve ark. (1987)'nın önerdiği șekilde tesadüf bloklari deneme desenine göre analiz edilmiş ve ortalamalar arasındaki farklilıklar LSD yöntemiyle karşılaștırılımıștır. Araștırmada incelenen Ozellikler arasındaki ilişkileri belirlemek için yıllara göre ayrı ayrı ortalamaları alınarak basit korelasyon katsayıları hesaplanmıştir.

\section{Bulgular ve Tartışma}

Çiçeklenme başlangıcı: Değişik ekim zamanlarından elde edilen iki yillik ortalama çiçeklenme başlangıçlarina ait değerler Çizelge 2'de verilmiştir. Çizelge 2'den de görüldügüu gibl, ekim zamanlarının çiçeklenme başlangıcına etkisi, her iki deneme yılında ve iki yillik ortalamada \%1 dózeyinde unemli bulunmuştur. Bu durumda, ortalama en uzun çiçeklenme başlangici her iki yilda ve yillar ortalamasında da 5 Martda $(67,69$ ve 68 gün) ekilen parsellerden elde edilmiştir. Ekim zamanının gecikmesi çiçeklenme başlangıçlarınin kısalmasına neden olmuştur. Bu durum, vejetasyon süresinin kısalması yanında, ekim zamanının gecikmesine bağlı olarak bitkilerin daha yüksek sicakliklara ve daha az toplam yağışlara maruz kalmasından kaynaklandığı söylenebilir (Çizelge 1). Nitekim Bakır (1959), yembitkilerinde büyüme peryotları içerisinde ortaya cıkan kuraklık ve yüksek isının büyūme sürelerinin kisalmasina neden olduğunu bildirmektedir. Bligen (1999), Antalya şartlarinda ari ofunun farkì ekim zamanlarının çiçeklenme özellikleri üzerine yaptığı bir araştımada, Ocak, Şubat, Mart, Nisan ve Mayıs ayında yapılan ekimlerde çiçeklenme başlangıçlarını sırasiyla $99.00,80.00,68.33,64.00$ ve 45.33 gún olarak belirlemiştir.

Çizelge 1. Tokat-Kazova'nin iklim verileri

\begin{tabular}{|c|c|c|c|c|c|c|c|c|c|}
\hline \multirow[b]{2}{*}{ Aylar } & \multicolumn{3}{|c|}{ Ortalama sicaklik $\left({ }^{\circ} \mathrm{C}\right)$} & \multicolumn{3}{|c|}{ Yağıș (mm) } & \multicolumn{3}{|c|}{ Ortaiama nisbi nem $(\%)$} \\
\hline & 2001 & 2002 & $\begin{array}{l}\text { Uzun } \\
\text { yillar }\end{array}$ & 2001 & 2002 & $\begin{array}{l}\text { Uzun } \\
\text { yillar }\end{array}$ & 2001 & 2002 & $\begin{array}{l}\text { Uzun } \\
\text { yillar }\end{array}$ \\
\hline Mart & 11.3 & 9.3 & 6.9 & 19.3 & 29.2 & 397 & 64.4 & 63.8 & 58.5 \\
\hline Nisan & 13.5 & 11.1 & 12.5 & 39.6 & 68.4 & 620 & 68.0 & 76.6 & 57.8 \\
\hline Mayis & 14.4 & 15.6 & 16.4 & 92,2 & 16.8 & 61.1 & 75.9 & 65.1 & 58.8 \\
\hline Haziran & 20.2 & 18.8 & 19.6 & 5.6 & 57.6 & 40.5 & 60.6 & 76.4 & 562 \\
\hline Qrt./Top. & 14.9 & 13.7 & 13.9 & 156.7 & 1720 & 203,3 & 66.7 & 70.5 & 57.8 \\
\hline
\end{tabular}

Kōy Hizmetleri Araştırma Enstitosu verileri, Tokat, 2002 

uzerinde araştımalar, L. Ot verimi ile ilgili ozellikler"

Çizelge 2. Farklı ekim zamanlarından elde edilen ortalama çị̧eklenme başlangiçlan, biłkide salkım sayları ve bitki boylan

\begin{tabular}{|c|c|c|c|c|c|c|c|c|c|}
\hline \multirow[b]{2}{*}{ Ekim zamanı } & \multicolumn{3}{|c|}{$\begin{array}{l}\text { Clçeklenme başangici } \\
\text { (ekimden itibaren gunn) }\end{array}$} & \multicolumn{3}{|c|}{$\begin{array}{c}\text { Bitkide salkım sayısi } \\
\text { (adeUbitki) }\end{array}$} & \multicolumn{3}{|c|}{$\begin{array}{l}\text { Bitki boyu } \\
\text { (cm) }\end{array}$} \\
\hline & 2001 & 2002 & Ort & 2001 & 2002 & Ort. & 2001 & 2002 & Ort. \\
\hline 5 Mart & $67 a$ & $69 a$ & 68 a & $12.7 \mathrm{a}$ & $13.7 \mathrm{a}$ & $13.2 \mathrm{a}$ & $51.0 \mathrm{a}$ & $57.9 \mathrm{a}$ & $54.5 a$ \\
\hline 20 Mart & $59 \mathrm{~b}$ & $64 \mathrm{~b}$ & $62 \mathrm{~b}$ & $10.7 a b$ & $123 a$ & $11.5 \mathrm{ab}$ & $4.7 \mathrm{ab}$ & $56.5 \mathrm{a}$ & $50.6 \mathrm{ab}$ \\
\hline 5 Nisan & $52 \mathrm{C}$ & $58 \mathrm{c}$ & $55 \mathrm{c}$ & $8.4 \mathrm{~b}$ & $11.7 \mathrm{a}$ & $10.1 \mathrm{~b}$ & $40.4 b$ & $54.2 \mathrm{a}$ & $47,3 \mathrm{~b}$ \\
\hline 20 Nisan & $47 \mathrm{~d}$ & $52 \mathrm{~d}$ & $49 d$ & $4.3 \mathrm{c}$ & $5.9 \mathrm{~b}$ & $5.1 \mathrm{c}$ & $36.2 b$ & $41.1 \mathrm{~b}$ & $38.7 \mathrm{c}$ \\
\hline Ortalama & $56 \mathrm{~b}^{\text {T+ }}$ & $61 a$ & 59 & 9.0 & 10.9 & 10.0 & $43.1 \mathrm{~b}^{\circ}$ & $52.4 \mathrm{a}$ & 478 \\
\hline LSD & 2.1 & 4.3 & 2.0 & 3.3 & 3.2 & 1.9 & 9.9 & 12,1 & 6.4 \\
\hline
\end{tabular}

*Aynı satif lçerisindeki benzer harf ile gösterilen ortalamalar LSD testine göre p $\leq 0.05$ hata sinırian içinde birbirinden farksızdir:

* Ayn satır içerisindeki benzer harf ile gösterilen ortalamalar LSO teșine göra p 0.01 hata sinurlan içinde birbirinden farksizdır.

"Aymi sotun içerisindeki benzer harf ile gosterilen ortalamalar LSD testine göre $p 50.01$ hata sınıriarı içinde birbitinden farksızdif:

Bitkide salkim sayisi: Farkl ekim zamanlarının bilkide salkım sayısı uzerine etkisi iki yıllık ortalamalar olarak Çizelge 2'de verilmiştir. Cizelge 2 incelendiğinde, ekim zamanlarinin bitkide salkım sayisına etkisi her iki yilda ve yillar ortalamasinda istatistiki açıdan çok önemif bulunmuştur. Ortalama en yoksek salkım sayisi 13.2 ade! ile 5 Mart, en düșlak ise 5.1 adet ile 20 Nisanda ekilen parsellerden saptanmıştır. Denemede ekim zamanları ilerledikçe, bir başka deyişle ekim zamanına bağlı olarak bitkilere sağlanan vejetasyon sûresi kısaldıkça salkım sayisı değerlerinde bir dūşme eğilimi göze çarpmaktadır. Bu durumda, yazlik ekimlende bilki başına fazla cicek salkımı eide etmek için bitkileri erken ekmenin bir avantaj sağlayacağ gecikmesiyle birlikte bitki boyu, yaş ot ve kuru ot verimierinde meydana gelen doșașier, ciçak salkimi sayisında da azaimalara neden olmuştur (Çizelge 2, 3). Nitekim, bitkide salkım sayısı ile bitki boyu, yaş ot ve kuru ot verimleri arasında ofumlu ve önemli ilișkiler elde edilmiştir (Çizelge 4), Karadaḡ ve Būyăkburç (1999). Tokat koşullarında arı otunun yazlık adaptasyonu ile ilgili olarak yourūtmūs oldukları bir denemede $\mathrm{m}^{2}$ de çicek salkımı sayısı ile bitki boyu, yaş of ve kuru ot verimi arasinda çok onemli ve olumlu bir ilişkinin varlığın bildirmektedirler

Bitki boyu: Arı otunda farklı ekim zamanlarinin bitki boyu Uzerine etkisi Cizelge 2'de verilmiştir. Cizelge '2'de görüldağa gibi, değișik ekim zamanlarının bitki boyuna etkisi her iki deneme yilinda ve iki yıllik ortalamada çok önemli çıkmıștır. Buna göre, en yúksek bitki boyu her iki yilda ve yillar ortalamasinda da 5 Mart $(51.0,57.9$ ve 54.5 $\mathrm{cm})$, en dūşük ise 20 Nisanda $(36.2,41.1$ ve $38.7 \mathrm{~cm}$ ) ekilen parsellerden elde edilmiștir. Ekim zamanimin gecikmesiyle birlikte bitki bayunda bir azlama meydana gelmiştir. Bu durum, ekim zamanının gecikmesine baĝlı olarak bitkilerin yağışlardan daha az faydalanma ve vejetatif peryodun daha kisa olmasindan kaynaklanmaktadır. Çizelge 2'den de görüldüga gibi, 2002 yilında farklı ekim zamanlarından elde edilen ortalama bitki boyları $52.4 \mathrm{~cm}$ ile 2001 yilimin ortalama değerlerinden $(43.1 \mathrm{~cm})$ önemli düzeyde yüksek bulunmuştur. Ikinci yilda vejetasyon dönemi boyunca düşen toplam yaḡışlann birinci yila göre daha yăksek olması (Cizelge 1) bitki boylarının artışına neden olmuştur. Karadaǵ ve Büyokburf̧ (1999), arı otunda yazlik olarak yürítmùş olduklan bir denemede $185.9 \mathrm{~mm}$ 'lik yağışin dūştüğo 1997 yilinda ortalama bitki boyunu $87.43 \mathrm{~cm}$, 124.7 mm'lik yağışın düştúğò 1998 yilinda ise $48.08 \mathrm{~cm}$ olarak belirlemişlerdir.
Araştırmamizda saptanan bitki boyu değerleri Bilgen (1999)'in elde ettiği sonuçlar ile benzerlik gösterirken, bazı araştıriciların (Sağlamtimur ve ark. 1988. Karadağ ve Buyalkburç 2001 a, 2001 b) sonuçlarindan daha dōşük bulunmustur. Bu duruma neden olarak, denemelerin yürütüldüğo ekolojik koß̧ullar yanında, söz konusu araştıncılann denemeleri kışlik olarak yürütmesi, dolayisiyla gerek vejetasyon süresinin uzunluğu ve gerekse bitkinin yetişme dönemi içerisinde düşen toplam yağışların fazla olması gösterilebilir.

Yaş ot verimi : Farkł ekím zamanindan elde edilen arı otunun iki yilik ortalams yaş of verimlerine ait değerler Çizelge 3 'de verilmiştir, Çizelge 3 incelendiğinde, ūrün yıllarında ve iki yılın ortalamasında ekim zamanlannın yaș ot verimine etkisi istatistiksel olarak ónemii ve çok önemli bulunmuştur. Ortalama en yơksek yaş ot verimi 5 Mart $(837.2 \mathrm{~kg} / \mathrm{da})$, en dūşük ise 20 Nisanda $(331.5 \mathrm{~kg} / \mathrm{da})$ ekilen parsellerden elde edilmiştir. Ekim zamanı llerledikçe yaş of verim degerierinde azalma kaydedilmiștir. Erken ekimiende vejetssyon süresinin uzaması yaninda, söz konusu dönemde bitkilerin geç yapılan ekimlere göre yağışardan daha fazla istifade etmesine bağlı olarak verim değerlerinde artışlar görülmüștür. Diğer yandan, anı otunda bitki boyu ile yaş of verimi arasında pozitif bir ilişki bulunmuştur (Çizelge 4). Bu ilişkiye bağlı olarak, ekim zamanının gecikmesi bitki boyumun azalmasına, sonuç olarak da yas ot veriminde azalmalara neden olmuștur. An otu bitkisiyle ilgili yapilan çalişmalarda pek çok sayida araştıncı, bitkl boyu ile yaş ot verimi arasında pozifif ve önemli ilişkilerin bulunduğunu bildirmektedirler (Karadağ ve Bôyükburç 1999, 2001 a, 2001 b).

Araştirmadan elde edilen yaş ot verimi, Karadag̀ ve Buyyúkburç (1999)'un elde ettikleri değerlere yakın, bazı araștırıcıların (Borowiec ve Pawlus 1973, Sağlamtimur ve ark. 1988, Karadağ ve Bayükburç 2001 a, 2001 b) tespit ettikleri değerierden ise daha düşalk bulunmuştur. Bu durum, araștırmaların yürütülmüş olduğu ekolojik koşullarm, özellikle de vejetasyon dönemi boyunca düşen toplam yağıșlardan ve de söz konusu araştıricilarin denemeleri kışlık olarak yürütmelerinden kaynaklandıḡı söylenebilir.

Kuru ot verimi : Değișik ekim zamantarından elde edilen iki yillik ortalama kuru of verimlerine ait degaerler Çizelge 3'de verilmiştir. Çizelge 3'deki deŏerier incelendiğinde, ekim zamanlarınin denemenin 
Cizelge 3. Farklı ekim zamanlarından elde edilen ortalama yaş ot ve kuru ot verimleri

\begin{tabular}{|c|c|c|c|c|c|c|}
\hline \multirow[b]{2}{*}{ Ekim zaman } & \multicolumn{3}{|c|}{ Yaş ot verimi $(\mathrm{kg} / \mathrm{da})$} & \multicolumn{3}{|c|}{ Kuru of verimi (kg/da) } \\
\hline & 2001 & 2002 & Ort. & 2001 & 2002 & Ort. \\
\hline $\begin{array}{l}5 \text { Mart } \\
20 \text { Mart } \\
5 \text { Nisan } \\
20 \text { Nisan } \\
\end{array}$ & $\begin{array}{l}604.2 \mathrm{a} \\
454.0 \mathrm{a} \\
432.3 \mathrm{a} \\
199.5 \mathrm{~b}\end{array}$ & $\begin{array}{c}1070.3 \mathrm{a} \\
875.5 \mathrm{ab} \\
739.6 \mathrm{bc} \\
463.5 \mathrm{c}\end{array}$ & $\begin{array}{l}837.2 \mathrm{a} \\
644.8 \mathrm{ab} \\
585.9 \mathrm{~b} \\
331.5 \mathrm{c}\end{array}$ & $\begin{array}{r}183.1 \mathrm{a} \\
120.6 \mathrm{a} \\
135.4 \mathrm{a} \\
31.0 \mathrm{~b}\end{array}$ & $\begin{array}{r}258.3 a \\
197.5 b \\
162.6 b \\
77.9 c\end{array}$ & $\begin{array}{r}220.7 \mathrm{a} \\
159.1 \mathrm{~b} \\
149.0 \mathrm{~b} \\
54.5 \mathrm{c}\end{array}$ \\
\hline Ortalama & $422.5 \mathrm{~b}^{7}$ & $787.2 \mathrm{a}$ & 604.9 & 117.5 & 174.1 & 145.8 \\
\hline LSD & 204.8 & 283.0 & 173.0 & 73.9 & 59.2 & 39.0 \\
\hline
\end{tabular}

${ }^{\dagger}$ Aym satır içerisindeki benzer harf ile gösterilen ortalamalar LSD testine göre p $\$ 0.05$ hata sınırları içinde birbirinden farksızdır.

Aynı sätun içerisindeki benzer harf le gösterilen ortalamalar LSD testine göre p 0,05 hata sınırları içinde birbirinden farksızdır.

"Aynı sutun içerisindeki benzer harf lile gösterilen ortalamalar LSD testine göre p $\leq 0.01$ hata sınirları içinde birbirinden farksızdır.

her iki yılında ve iki yılın ortalamasında kuru ot verimine istatistiksel olarak çok önemli bir etkisi olmuştur. Bung göre en yüksek kuru ot verimi, her Iki yilda ve yillar ortalamasinda 5 Mart $(183.1,258.3$ ve $220.7 \mathrm{~kg} / \mathrm{da}$ ), en düşük ise 20 Nisanda $(31.0,77.9$ ve $54.5 \mathrm{~kg} / \mathrm{da})$ ekilen bitkilerden tespit edilmiştir.

Ekim zamamnn gecikmesiyle birlikte yas of veriminde olduğu gibi, kuru ot verimi değerlerinde de azalma kaydedilmiștir. Bu durum, kuru of verimi ile bitki boyu ve yas ot verimi arasında olumlu ve ónemil bir ilişkinin bulunduğu (Çizelge 4), dolayısıyla ekim zamanının gecikmesiyle birlikte gerek bitki boyunun ve gerekse yas of verimlerinin azalması, kuru ot verim değerlerinin de azalmasına neden olmuştur. Karadağ ve Büyükburç (2001 a, 2001 b) kuru ot verimi lle bllki boyu ve yaş of verimi arasında olumlu ve çok önemli ilişsilerin bulunduğunu bildirmektedirler. Diğer yandan ekim zamanının gecikmesiyle birlikte bitkilerin vejetasyon säresinin kısalmasina ve bitkinin yetişme dönemi içerisinde düşen toplam yağıslann azalmasının bir sonucu olarak da kuru ot veriminin dosşmesine neden olmuştur. Denemeden elde edilen kuru ot verimi deg̈erleri bazı araştıricılarin (Sağlamtimur ve ark. 1988, Karadağ ve Büyükburç 2001 a, 2001 b) elde etmis olduklari bulgulardan daha daşak bulunmuştur. Bu farklılık, yaş ot veriminde olduğu gibi kuru ot veriminin de çevre faktörlerinden özellikle de iklim değişikliklerinden ve denemelerin kışlık ve yazlık olarak yürütülmesinden kaynaklandığını söyleyebiliriz.

Özellikler arası ilişkiler: Arı otunda, farkıı ekim zamanlarına ait ozellikler arasındaki ikili ilişkilerin belirlendiği değerler ve basit korelasyon katsayıları Çizelge $4^{\prime}$ de verilmiştir. Çizelge 4 'de görüldoğa glbi, ciçeklenme başlangıcı ile bitkide salkım sayısı ve bitki boyu arasında denemenin ilk yılında olumlu ve onernli, ikinci yıl önemsiz; yaș ot ve kuru ot verimi ile denemenin ikinci yilinda olumlu ve önemli, birinci yil ise önemsiz bir ilișkinin bulunduğu belirlenmiştir. Bitkide salkım sayısı ile bitki boyu ve yaş ot verimi arasinda denemenin her iki yilinda da olumlu ve önemli bir ilişki elde edilirken, kuru ot verimi $(0.954)$ ile 2002 yilinda olumlu ve önemli, 2001 yılında ise önemsiz bir ilişki elde edilmiştir. Karadağ ve Büyükburç (1999), an otunda $m^{2}$ de çiçek salkımı sayısı ile bitki boyu, yas ot verimi ve kuru of verimi arasında olumlu ve önemii bir ilişkinin bulunduğunu bildirmişlerdir.
Çizelge 4. Araștırmada incelenen özellikler arasında bulunan korelasyon katsayilan ${ }^{\text {*) }}$

\begin{tabular}{|c|c|c|c|c|}
\hline $\begin{array}{l}\text { Tincelenen } \\
\text { ózellikler }\end{array}$ & $\begin{array}{l}\text { Bitkide } \\
\text { salkam } \\
\text { sayisi }\end{array}$ & $\begin{array}{l}\text { Bitki } \\
\text { boyu }\end{array}$ & $\begin{array}{l}\text { Yaş ot } \\
\text { verimi }\end{array}$ & $\begin{array}{l}\text { Kuru of } \\
\text { verimi }\end{array}$ \\
\hline $\begin{array}{l}\text { Çiçeklenme } \\
\text { başlangici }\end{array}$ & $\begin{array}{l}0.963^{\circ} \\
0.911\end{array}$ & $\begin{array}{l}0.997^{*} \\
0.895\end{array}$ & $\begin{array}{l}0.928 \\
0.993^{-}\end{array}$ & $\begin{array}{l}0.861 \\
0.989\end{array}$ \\
\hline $\begin{array}{l}\text { Bilkide salkım } \\
\text { sayısı }\end{array}$ & & $\begin{array}{l}0.964^{\circ} \\
0.995^{-}\end{array}$ & $\begin{array}{l}0.977^{\circ} \\
0.950^{\circ}\end{array}$ & $\begin{array}{l}0.936 \\
0.954\end{array}$ \\
\hline Bitki boyu & & & $\begin{array}{l}0.945 \\
0.932\end{array}$ & $\begin{array}{l}0.888 \\
0.934\end{array}$ \\
\hline Yas ot verimi & & & & $\begin{array}{l}0.988^{\circ} \\
0.999^{\prime \prime}\end{array}$ \\
\hline
\end{tabular}

"Sirasiyla 2001, 2002 yillarına ait korelasyon katsayiları. ps0.05, p 0.01 hata sınirlan içerisinde önemili.

Bitki boyu ile yaş ot ve kuru ot verimi arasında denemenin her iki yilinda da önemsiz fakat olumlu bir ilişki elde edilimiştir. Bitki boyu lle yaş ot ve kuru ot verimi arasında önemli ve olumlu bir ilişkinin bulunduğu bazı araştıncilar (Karadağ ve Büyükburç 2001 a, 2001 b) tarafından da bildirilmiștir. Yaş ot verimi lle kuru ot verimi arasinda 2001 ve 2002 yilinda olumlu ve onemli bir ilişki saptanmıştır. Yaş ot ile kuru ot verimi arasında özellikle 2002 yilında ilişki dúzeyi $\left(0.999^{*}\right)$ diğer yıla göre oldukça yüksektir. Vejetasyon süresince düşen yağışın 2002 yilında daha fazla olması, yas ot veriminin yükselmesine ve dolayısıyla kuru ot veriminde artışa neden olmuştur. Karadağ ve Büyükburç (1999, 2001 a, 2001 b) anilan ózellikler arasında önemli ve pozitif bir llişkinin bulunduğunu bildirmişlerdir.

Sonuç olarak, Tokat koşullarında yazlık olarak iki yıl süre ile yürütülen bu araștırmada; arı otunun of Gretimi için yetiştiriciliğinde bitkilerin Mart ayinın ilk haftasinda ekilmesinin uygun olduğu, geç tarihlerde yapilan ekimlerin gerek of ve gerekse bitkide salkim sayılarında azalmalara neden olduğu saptanmiştır. Ekim zamanının ilerlemesine bağlı olarak, arı otunun kuraklıktan ve yüksek sıcaklıklardan olumsuz yönde etkilendigi söylenebilir. 


\section{Kaynaklar}

Bakır, Ö. 1959. Ekolojik Faktörlerin Önemli Yembitkilerinin Büyüme ve Gelişmesine Tesirleri Üzerinde Araştırmalar. Ankara Üniversitesi Ziraat Fakültesi Yayınları: 237. Bilimsel Araştırma ve Inceleme: 200, Ankara Öniversitesi Basımevi, 116, Ankara.

Bilgen, M. 1999. An otununda (Phacelia tanacetifolia Bentham) farklı ekim zamanlarının çiçeklenme özellikleri üzerine etkisi. Türkiye 3. Tarla Bitkileri Kongresi, 15-18 Kasım 1999, 312-317, Adana.

Borowiec, S., M. Pawlus, 1973. Changes in soil content under some crops vegetation. Herbage Abstracts, 43 (10) 315 , No:2832.

Crane, E., P. Walker and R. Day, 1984. Directory of Important World Honey Sources. International Bee Research Association, London, UK, 384 pp.

Düzgüneş, O., T. Kesici, O. Kavuncu ve F. Gürbüz, 1987. Araştırma Deneme Metodları, Ankara Oniversitesi Ziraat Fakültesi Yayınları No: 1021. Ders Kitabı: 295, Ankara.

Howes, F.N. 1979. Plants and Beekeeping. Faber and Faber, London \& Boston, 236.

Karadağ, Y., U. Büyükburç, 1999. Tokat koşullarında yetiştirilen arı otunun (Phacelia tanacetifolia Bentham) verim ve adaptasyonu üzerine bir araștırma. Gaziosmanpaşa Üniversitesi Ziraat Fakültesi Dergisi, 16 (1) 155-169.

Karadağ, Y., U. Bũyükburç, 2001 a. The effect of different sowing dates on herbage and seed yields of phacelia (Phacelia tanacetifolia Bentham). Prospect of the $3^{\text {th }}$ Millenium Agriculture. October 25-27, 54-57, Cluj-Napoca, Romania.

Karadağ, Y., U. Büyükburç, 2001 b. Arı otunda (Phacelia tanacetifolia Bentham) farklı sıra aralığının ot ve tohum verimlerine etkileri. Türkiye 4. Tarla Bitkileri Kongresi, 17-21 Eylül 2001, Cilt 3 Çayır-Mer'a, Yembitkileri, 143-148, Tekirdağ.
Munz, A.P. 1973. A California Flora. Univ. of California Press. Berkeley and Los Angeles.

Packer, J. 1973. The flight and foraging behaviour of the alkali bee (Nomina melanderi Ckll.) and the alfalfa leaf cutter bee (Megachile rotundata F.). Herbage Abstracts, 43 (9) 267, No: 2389 .

Peter, J. 1973. Studies on floral nectar secretion in field crops. Herbage Abstracts, 43 (10) 333, No: 3013.

Sağlamtimur, T., V. Tansı ve H. Baytekin, 1988. Yembitkileri Yetiştirme. Çukurova Öniversitesi Ziraat Fakültesi Ders Kitabı, No:73, Adana.

Sağlamtimur, T., V. Tansı ve H. Baytekin, 1989. Çukurova Koşullarında kışlık ara ürün olarak yetiştirilen an otu (Phacelia califomica Cham)'nda biçim zamanının bitki boyu ve ot verimine etkisi üzerinde bir araştırma. Çukurova Üniversitesi Ziraat Fakültesi Dergisi, 4 (1) 76-83.

Tansı, V., T. Sağlamtimur, M. Kızılşimşek ve U. Kumova, 1995. Observation on Phacelia tanacetifolia Bentham as a food plant for honey bees in Southern Turkey. Congres Apimondia. Lousanne. 15-19.8.1995.

Williams, I.H., D.G. Chiristian, 1991. Observation on Phacelia tanacetifolia Bentham (Hydropyllaceae) as a food plant for honey bees and bumble bees. Journal of Agric. Research. 30 (1) 3-12.

Iletişim adresi :

Yaşar KARADAĞ

Gaziosmanpaşa Üniversitesi, Ziraat Fakültesi

Tarla Bitkileri Bölümü-Tokat 